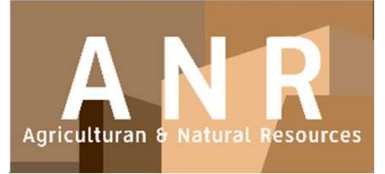

PAPER - OPEN ACCESS

\title{
Pertumbuhan Bibit Surian Dari Cabutan Alam Di Nagari Lubuk Gadang Selatan Kabupaten Solok Selatan Sumatera Barat
}

\author{
Author : : Zulmardi dan Desyanti \\ DOI $\quad: 10.32734 /$ anr.v3i1.826 \\ Electronic ISSN : :2654-7023 \\ Print ISSN : $2654-7015$
}

Volume 3 Issue 1 - 2020 TALENTA Conference Series: Agriculturan \& Natural Resource (ANR)

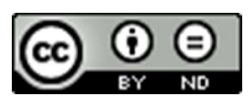

This work is licensed under a Creative Commons Attribution-NoDerivatives 4.0 International License.

Published under licence by TALENTA Publisher, Universitas Sumatera Utara

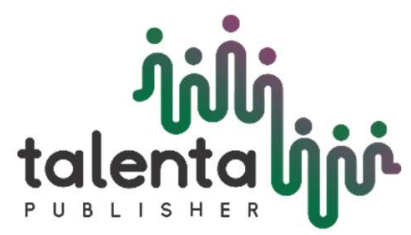




\section{Pertumbuhan Bibit Surian Dari Cabutan Alam Di Nagari Lubuk Gadang Selatan Kabupaten Solok Selatan Sumatera Barat}

\author{
Zulmardia,* dan Desyantia \\ Fakultas Kehutanan Universitas Muhammadiyah Sumatera Barat, Indonesia
}

zu16656@gmail.com

\begin{abstract}
Abstrak
Perbanyakan bibit pohon dapat berasal dari biji dan benih. Perolehan bibit dari cabutan alam merupakan salah suatu upaya agar ketersediaan bibit dapat dipenuhi dalam rangka penanaman pohon berkayu di kebun masyarakat dan di kawasan konservasi. Penelitian ini dilakukan pada Kelompok Konservasi Mandiri (KKM) dan Mekar Berbuah di Nagari Lubuk Gadang Selatan, Kabupaten Solok Selatan Provinsi Sumatera Barat. Penelitian dilakukan pada bulan Juli sampai Oktober 2018. Metode yang digunakan adalah metode kuntitatif terhadap rata-rata 3.420 bibit dari enam bedeng semai. Data yang diperoleh adalah tinggi bibit dan jumlah daun, sampel data bibit sebanyak 31\%, dengan data awal tinggi bibit rata-rata $3,6 \mathrm{~cm}$ dan jumlah daun rata-rata 2,4 helai. Hasil penelitian menunjukkan bahwa nilai rata-rata tertinggi pada tinggi bibit adalah $43,2 \mathrm{~cm}$ dan nilai terendah adalah 22,5 $\mathrm{cm}$, dengan peningkatan tinggi bibit sebesar $39,6 \mathrm{~cm}$ atau rata-rata $9,9 \mathrm{~cm}$ per bulan pada bibit Surian dalam pengamatan yang dilakukan selama empat bulan. Sedangkan rata-rata jumlah daun adalah sebanyak 8,5 dengan peningkatan jumlah daun sebesar 6 helai selama empat bulan, tingkat pertumbuhan termasuk kategori baik.
\end{abstract}

Kata Kunci: Bibit Surian cabutan alam; pertumbuhan; Solok Selatan

\section{Pendahuluan}

Persemaian (nursery) adalah tempat atau areal untuk kegiatan memproses benih (atau bahan lain dari tanaman) menjadi bibit/semai yang siap ditanam di lapangan. Kegiatan di persemaian merupakan kegiatan awal di lapangan dari kegiatan penanaman pohon hutan karena persemaian sangat penting dan merupakan kunci pertama di dalam upaya mencapai keberhasilan penanaman hutan. Penanaman benih dilapangan dapat dilakukan secara langsung (direct planting) dan secara tidak langsung yang berarti harus disemaikan terlebih dahulu di tempat persemaian [1].

Penanaman secara langsung dilapangan biasanya dilakukan apabila biji-biji (benih) tersebut berukuran besar dan jumlah persediaannya melimpah. Meskipun ukuran benih besar tetapi kalau jumlahnya terbatas maka benih tersebut seyogyanya disemaikan terlebih dahulu. Pemindahan/penanaman bibit berupa semai dari persemaian ke lapangan dapat dilakukan setelah semai-semai dari persemaian tersebut sudah kuat/siap ditanam [2]-[3]. Penyediaan semai/tahun sebanyak 20.000 batang merupakan kebutuhan minimum untuk memulai persemaian berukuran kecil [2].

Keberadaan bibit Surian yang melimpah di hutan tidak sebanding dengan jumlah bibit yang ada di persemaian. Ketersediaan bibit Surian yang diperlukan untuk penanaman di lokasi konservasi maupun di lahan tumpang sari sangat sedikit dan belum terjamin mutunya. Sejalan dengan itu, pertumbuhan pohon Surian juga memerlukan waktu yang lama yaitu 15-20 tahun untuk dapat dipanen. Sedangkan pertanian tumpang sari juga memerlukan masa 'bera' yang menghabiskan waktu petani beberapa bulan. Pohon surian memiliki ragam manfaat baik dari hasil kayu maupun hasil hutan bukan kayu. Kayu surian dapat dimanfaatkan sebagai kayu pertukangan.

Lokasi lahan perkebunan dan pertanian masyarakat berbatasan langsung dengan kawasan konservasi yaitu Taman Nasional Kerinci Seblat (TNKS), kondisi ini menjadikan kawasan konservasi dapat tertekan dengan terjadinya 
penurunan jumlah pohon berkayu apabila tidak mendapat dukungan dari masyarakat. Untuk itu upaya penghijauan di kawasan konservasi sebaiknya dilakukan secara terus menerus dengan penanaman pohon berkayu antara lain adalah pohon Surian. Selama ini kegiatan rutin yang sudah dilakukan adalah melaksanakan penanaman pohon di jalur sabuk hijau oleh masyarakat bersama dengan Balai Besar TNKS. Terkait dengan kegiatan penanaman, ketersediaan bibit berkualitas merupakan hal yang penting untuk diperhatikan agar keberhasilan penanaman dapat dicapai. Bibit yang berasal dari cabutan alam memerlukan adaptasi lingkungan yang baik. Bibit cabutan alam sangat rentan mengalami kematian apabila tidak dapat beradaptasi dengan lingkungan barunya. Penelitian ini bertujuan untuk mengamati dan mengetahui pertumbuhan bibit surian hasil cabutan alam di kebun bibit di Nagari Lubuk Gadang Selatan Kabupaten Solok Selatan Sumatera Barat.

\section{Metode Penelitian}

\subsection{Waktu dan Lokasi}

Penelitian dilakukan di persemaian milik kelompok tani. Penelitian dilaksanakan pada bulan Juli sampai Oktober 2018.

\subsection{Bahan dan Alat}

Bahan yang digunakan dalam penelitian ini adalah bibit Surian dari cabutan alam, polibag, media tanam dari tanah top soil, kompos, sekam, dan kapur dengan perbadingan 1:1:1:1. Setelah media tanam di persiapkan, semua media dicampur dan diaduk agar tercampur dengan rata, media yang telah diaduk di ayak dan dimasukan kedalam polybag. Alat yang digunakan adalah meteran, $\mathrm{pH}$ meter, dan alat tulis.

\subsection{Prosedur Kerja}

\subsubsection{Persiapan Bibit}

Bibit cabutan alam diambil dari lokasi yang tidak jauh dari lokasi persemaian. Cabutan alam diperoleh dari bibit yang tumbuh disekitar pohon induk yang telah ditetapkan oleh Balai Sertifikasi Benih dan Tanaman Hutan (BSBTH) Provinsi Sumatera Barat sebagai pohon indukan. Pada saat pengambilan cabutan di lapangan, keadaan tanah harus lembab. Jika tanah disekitar bibit kering sebaiknya disiram terlebih dahulu sampai basah agar pada saat bibit dicabut akar dan ektomikoriza tidak rusak. Lokasi pengambilan bibit sebaiknya tidak tergenang air atau tidak dalam keadaan hujan deras. Waktu yang ideal untuk pengambilan bibit adalah pagi dan sore hari. Cara mencabut anakan bibit cabutan alam adalah dengan mencongkel tanah di sekitar perakaran bibit mengunakan parang, kemudian dicabut satu persatu. Proses penarikan bibit dari tanah dilakukan pada bagian leher akar (bagian yang paling dekat dengan permukaan tanah), kemudian ditarik lurus searah batangnya. Pencabutan bibit tidak boleh dilakukan dengan cepat atau dipaksa tetapi harus dilakukan secara hati-hati. Selanjutnya penyeleksian bibit hasil cabutan alam dilakukan guna memilah bibit yang memenuhi syarat. Bibit yang memenuhi syarat untuk diproses lebih lanjut adalah bibit yang memiliki organ utuh, tidak terserang penyakit dan memiliki akar yang utuh (tidak terputus). Setelah bibit selesai doseleksi, bibit cabutan kemudian disusun dengan rapi setelah itu masukan ke dalam kemasan dengan posisi akar kebawah dan daun ke atas. 


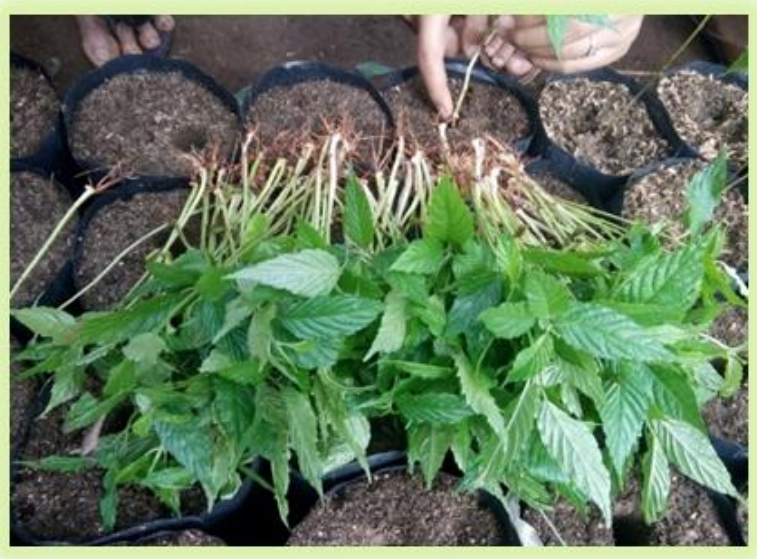

(a)

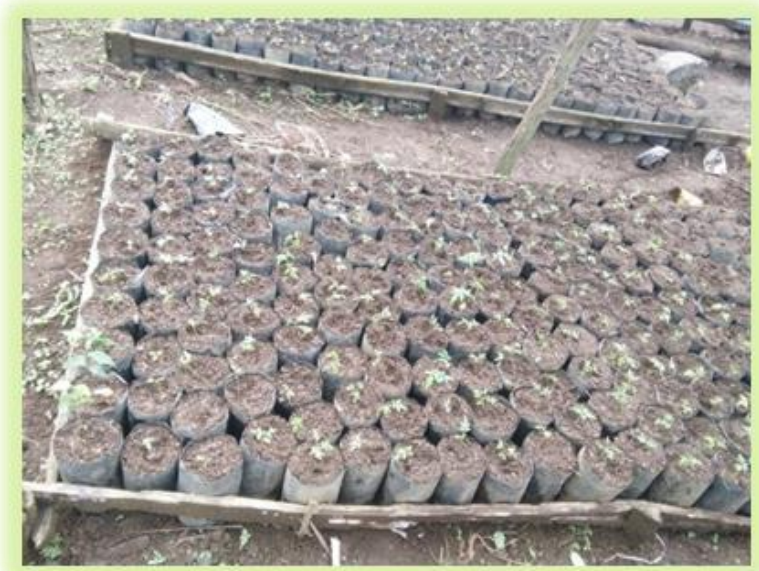

(b)

Gambar 1. Anakan bibit Surian dari cabutan alam siap untuk ditanam (a) dan penyusunan bibit dalam polybag pada bedeng tanam (b).

\subsubsection{Penanaman Bahan Bibit Cabutan}

Penanaman bahan bibit cabutan adalah kegiatan menanam kembali bahan bibit cabutan ke dalam pollybag yang sudah disiapkan dan telah tersusun rapi pada bedeng. Lubang tanam dibuat sebelum penanaman dan disesuaikan dengan panjang akar bibit cabutan dengan menggunakan alat pelubang yang sudah diruncingkan dengan kondisi media tanam yang tidak terlalu kering atau tidak terlalu basah (lembab). Penanaman bibit dilakukan dengan cara memasukan bibit cabutan alam kedalam lubang tanam pada pollybag, dengan kedalaman sebatas leher akar, kemudian tutup kembali sambil ditekan dengan tangan pelan-pelan agar tanah sekitarnya melekat dengan sempurna. Susunlah pollybag yang sudah diisi bibit dengan rapi pada bedeng semai, dan Setelah berada di bedeng semai bibit harus disiram dengan air satu kali dalam sehari.

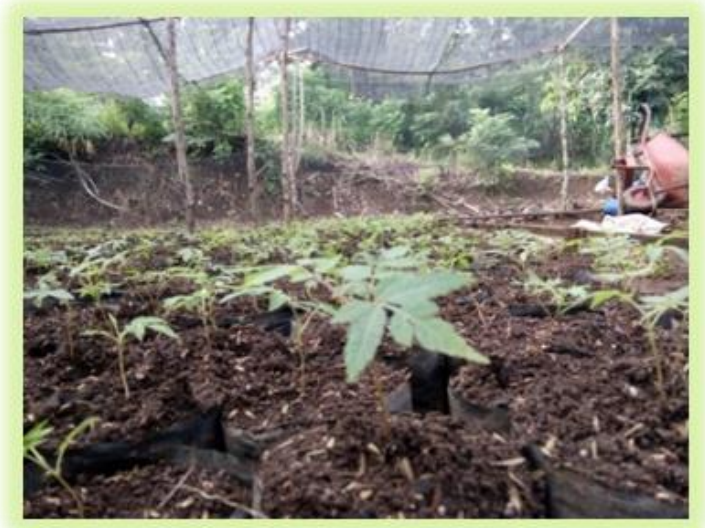

(a)

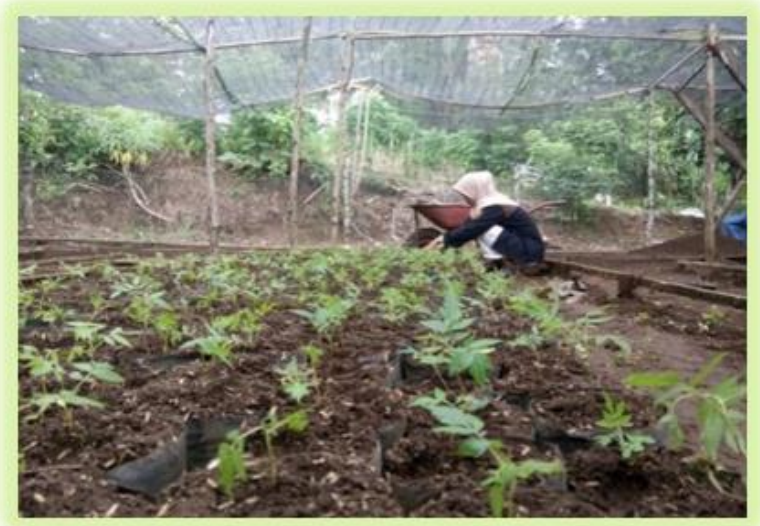

(b)

Gambar 2. Penanaman bibit Surian dalam polibag sebanyak enam bedeng dengan jumlah 570 batang bibit per bedeng, dan total 3.420 bibit Surian.

Pengukuran dilakukan terhadap bibit yang sudah disusun dalam pollybag didalam bedeng semai. Bedeng semai masing masing berisi sekitar 570 bibit Surian dan terdapat enam bedeng semai. Dengan demikian terdapat sekitar 3.420 bibit yang sudah siap di tempatkan pada persemaian. Selanjutnya dilakukan pengukuran terhadap semua bibit dengan aspek yang diukur yaitu: pengukuran tinggi batang bibit $(\mathrm{cm})$ dan penghitungan jumlah daun (helai). Pengukuran tinggi dilakukan dengan menggunakan penggaris/meteran dan penghitungan jumlah daun melalui pengamatan objektif. Tujuan dilakukan pengukuran ini adalah untuk mengetahui tingkat keberhasilan pertumbuhan bibit dari persemaian yang sudah dilakukan. 


\section{Hasil dan Pembahasan}

Pengukuran dilakukan sebanyak tiga kali terhadap semua bibit yaitu pada bulan Agustus, September, dan Nopember 2018. Hasil pengamatan menunjukkan bahwa peningkatan rata-rata tinggi batang adalah 39,6 (cm) sedangkan jumlah daun meningkat sebanyak 6 helai daun dari awal penanaman bibit di persemaian. Gambar pertumbuhan bibit pada persemaian tersaji pada Gambar 3.

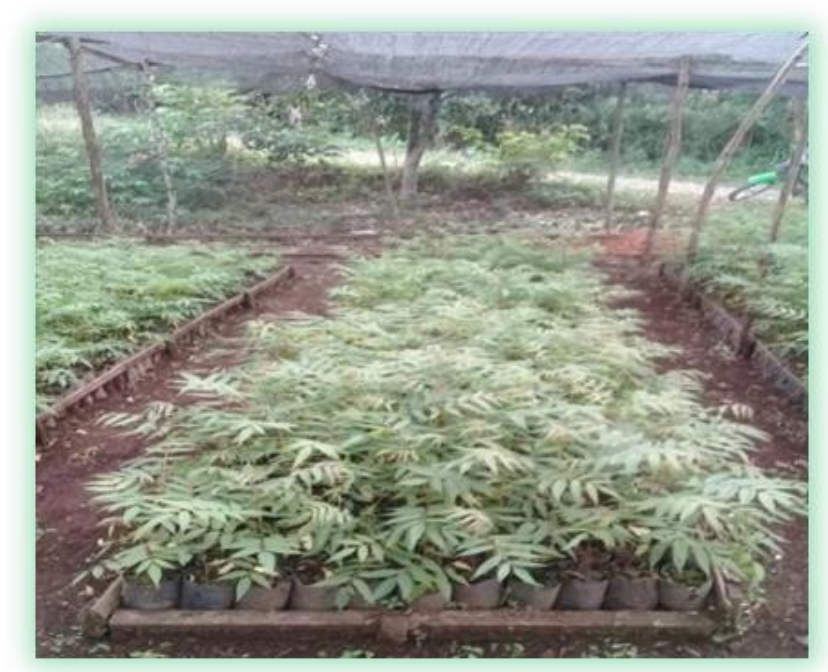

Gambar 3. Pemeliharaan bibit Surian dalam pollybag pada bulan September 2018.

Berdasarkan hasil pengamatan dan pemeliharaan serta pengukuran yang dilakukan terhadap semua bibit surian pada bulan November 2018, bibit yang mengalami pertumbuhan dibawah normal hanya sekitar $1 \%$. Dengan sedikitnya pertumbuhan dibawah normal pada bibit surian, maka dapat dinyatakan bahwa pertumbuhan bibit tergolong baik. Pengukuran dan pemeliharaan dijalankan selama lebih kurang enam bulan. Setelah tinggi bibit sudah memenuhi syarat untuk ditanam dilapangan, maka bibit surian sudah dapat dipindahkan dan menjadi bibit dalam penanaman di lokasi hutan di sekitar Taman Nasional Kerinci Seblat sebagai kawasan konservasi guna untuk pengayaan tanaman pohon Surian dan di kebun masyarakat.

Hasil pengukuran pertama bibit surian yang dilakukan pada bulan Agustus 2018, menunjukkan bahwa nilai tertinggi dari rata-rata tinggi bibit adalah 4,803 (cm) dan nilai tertinggi rata-rata jumlah daun adalah 2,56 (helai) daun (gambar 4). Sedangkan hasil pengukuran pertama bibit Surian pada bulan September 2018 menunjukkan bahwa nilai tertinggi rata-rata tinggi bibit adalah $6,4(\mathrm{~cm})$ dan nilai tertinggi rata-rata jumlah daun adalah 4,7 (helai) daun (gambar $5)$.

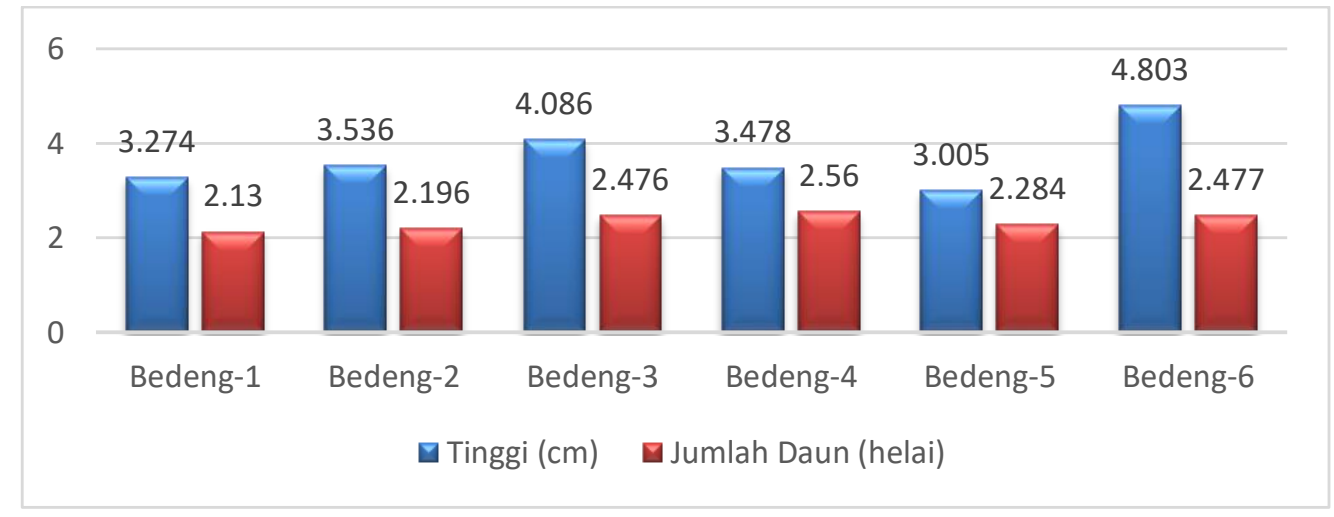


Gambar 4. Histogram hasil pengukuran pertama bulan Agustus 2018 rerata tinggi (cm) dan jumlah daun (helai) bibit Surian dari bedeng 1 sampai bedeng 6 .

Hasil pengukuran kedua dan ketiga yang dilakukan pada pada bulan Nopember 2018 menunjukkan bahwa nilai tertinggi rata-rata tinggi batang adalah $43,2(\mathrm{~cm})$ dan nilai terendah adalah $22,5 \mathrm{~cm}$. pada pengukuran jumlah daun, rata-rata adalah sebanyak 8,5 helai. Rata-rata pertumbuhan bibit pada bulan Nopember 2018 tersaji pada Gambar 6.

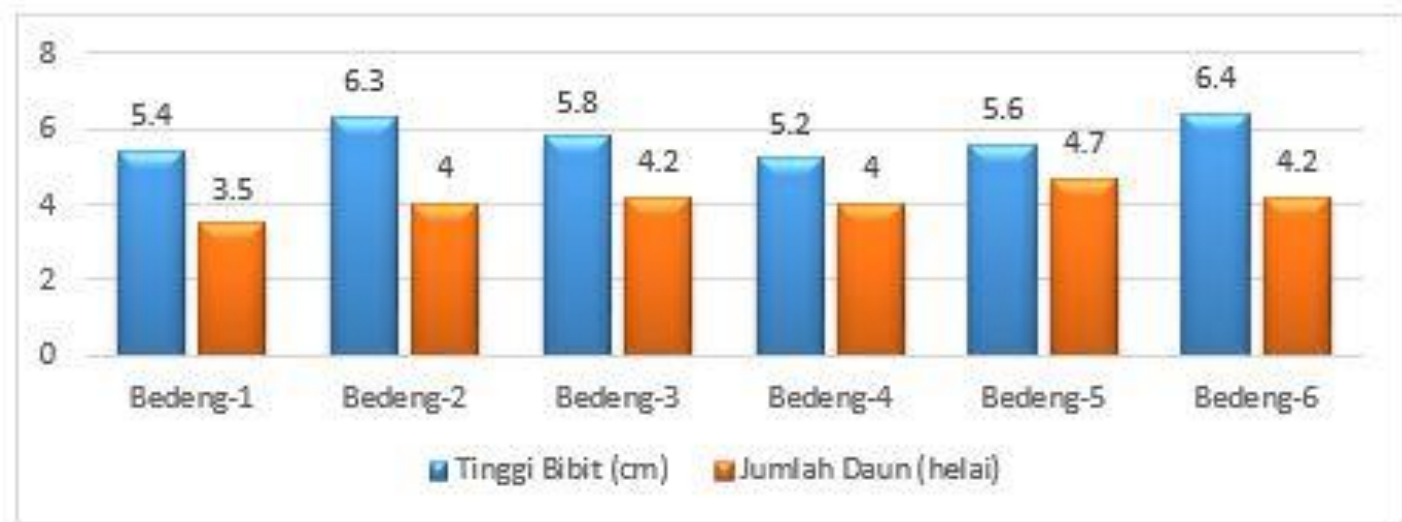

Gambar 5. Histogram hasil pengukuran rerata tinggi (cm) dan jumlah daun (helai) bibit Surian dari bedeng 1 sampai bedeng 6 (September 2018)

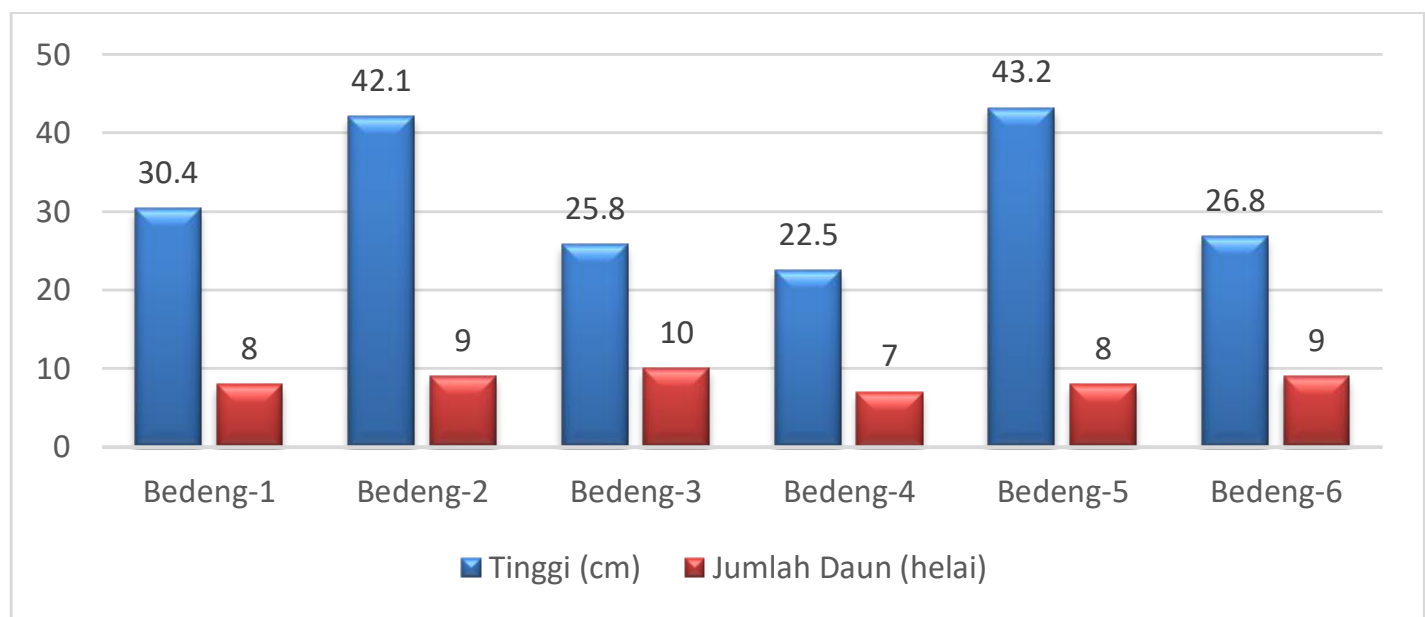

Gambar 6. Histogram hasil pengukuran rerata tinggi (cm) dan jumlah daun (helai) bibit Surian dari bedeng 1 sampai bedeng 6 (Nopember 2018)

\section{Kesimpulan dan Saran}

\subsection{Kesimpulan}

Pertumbuhan bibit surian hasil cabutan alam tergolong baik dan dapat digunakan dalam kegiatan penanaman. Bibit surian dapat beradaptasi dengan baik pada lingkungan baru dipersemaian dan hanya $1 \%$ bibit yang mengalami pertumbuhan dibawah normal. Pertumbuhan bibit Surian di persemaian pada enam bedeng semai berjumlah 3.420 batang bibit dan berukuran tinggi rata-rata $31,8 \mathrm{~cm}$ dan jumlah daun rata-rata 8,5 helai.

\subsection{Saran}

Penelitian lanjutan sebaiknya dilakukan sampai umur bibit pindah tanam yaitu sekitar delapan sampai sepuluh bulan dan perlu dilanjutkan dengan penanaman di lapangan untuk mengetahui kesesuaian media yang digunakan dengan pertumbuhan bibit dan benih di lapangan. 


\section{Ucapan Terima Kasih}

Terima Kasih disampaikan kepada Direktorat Riset dan Pengabdian Masyarakat Direktorat Jenderal Penguatan Riset dan Pengembangan Kementerian Riset, Teknologi, dan Pendidikan Tinggi RI atas dukungan biaya dan Kelompok Masyarakat Konservasi Mandiri dan Mekar Berbuah atas dukungan pelaksanaan di lapangan.

\section{Referensi}

[1] Anonim. (2010) "Pengenalan Jenis Benih. Benih Tanaman Program HTI." Diakses pada www.indonesianforest.com

[2] Pelupessy, L. (2007) “Teknik Persemaian” dalam Pelatihan Penanaman Hutan di Maluku \& Maluku Utara-Ambon 12-13 Desember 2007, Fakultas Pertanian Universitas Pattimura, Sulawesi.

[3] Dorthe Jøker. (2002) "Indonesia Forest Seed Project. Informasi Singkat Benih. Tamarindus indica L. Direktorat Perbenihan Tanaman Hutan. No. 21, Mei 2002. T.H.R. Ir. H. Juanda, Dago Pakar, E-mail: ifsp@indo.net.id”, Bandung, Indonesia 